\title{
Career preferences and factors influencing speciality choices among the medical students in Telangana: A cross sectional study
}

\author{
Kishore Y. Jothula ${ }^{1}$, Praveena Ganapa ${ }^{2, *}$, Sreeharshika ${ }^{3}$, Pramodh Reddy $\mathbf{P}^{4}$, Abhishek $\mathbf{P}^{5}$ \\ ${ }^{\mathbf{1}}$ Associate Professor, ${ }^{\mathbf{2}}$ Assistant Professor, ${ }^{3}$ Tutor, ${ }^{4,5}$ Post graduate, Dept. of Community Medicine, Kamineni Institute of Medical \\ Sciences, Narketpally, Telangana
}

*Corresponding Author:

Email: praveenakmc@gmail.com

\begin{abstract}
Introduction: Aim of the study was to know career preferences and factors influencing speciality choices among the medical students in Telangana.

Materials and Methods: An Institution based cross sectional study was carried out at Kamineni Institute of Medical Sciences, Narketpally with 150 first year medical students as study subjects from November 2017 to December 2017.

Study tool was pretested semi structured questionnaire. Data was entered in Microsoft excel and analysis was done using SPSS statistical package version 22 .

Result: Out of 150 participants, $42(28 \%)$ were boys and 108 (72\%) were girls, with a mean age of $17.94 \pm 0.82$. Majority $(62.6 \%)$ of the participants were city residents. $57.3 \%$ of the study population wants to pursue specialization. Among the students who wants to pursue specialization majority were interested in clinical branches compared to Community Medicine which was only $6.9 \%$. There was significant difference between males and females selection of specialities like cardiology, gynaecology and orthopaedics. Most common factors for selection of speciality courses were reputation of the speciality (91.8\%) and Self interest $(76.7 \%)$.

Conclusion: Majority of the medical students wants to pursue specialization and most of them showed interest in the clinical branches. Significant difference between males and females selection of specialities like cardiology, gynaecology and orthopaedics. Most common factors for selection of speciality courses were reputation of the speciality and Self interest followed by early settlement and to make more money.
\end{abstract}

Keywords: Career, Speciality, Community Medicine, Clinical, Gynaecology, Cardiology.

\section{Introduction}

Medical education is one of the core part of educational system of any country. Medical education requires undergraduate students to study a wide range of medical specialties. It is often assumed that students do not make their career preferences until after they have graduated from medical school. ${ }^{1}$ The number of undergraduate medical seats is increasing in many countries, thus increasing the demand for specialty training. Trends in selection of particular specialties have implications in terms of arranging training and supervising positions and information on these trends is necessary to guide policy. ${ }^{2}$

The ratio of the post-graduate to undergraduate medical seats in India is 29:100, with the number of medical graduate seats in India are approximately 32,000 . Undergraduate medical training in India lasts for 4.5 years, followed by a year of compulsory internship.

Post-graduate specialization is perceived as essential for success, and there is high competition for post graduate seats, especially in clinical specialities. ${ }^{3}$ Factors influencing choice of subject for specialization includes factors like what made the students decide to be a doctor, at what age student chose to study medicine and problems faced during medical school. ${ }^{4}$

Medical students' career preferences per se are important to study, as their choices will influence the maintenance of an adequate physician supply and the future provision of health care. ${ }^{5}$ The aim of current study is to study the career preferences and factors influencing speciality choices among the medical students and to study the gender differences in choosing the specialities.

\section{Materials and Methods}

Study design: Institution based cross sectional study

Study setting: Kamineni institute of medical sciences, Narketpally

Study population: First year medical students of kamineni institute of medical sciences, Narketpally

Sample size: Out of 200 first year students, 20 had participated in the pilot study and 30 students were absent on the day of data collection. Hence a total of 150 first year students were included after taking consent, hence sample size was 150 .

Study period: This study was carried out for 2 months from November 2017 to December 2017.

Study tool: Pretested Semi structured questionnaire. Pilot study was conducted on 20 students initially for standardization of the questionnaire. Questionnaire consists of: Socio demographic information, willingness for pursuing specialization, selection of speciality and factors that influenced for selection of particular Speciality 
Method of data collection: Questionnaire was administered to the students after explaining them the importance of study and each question in the questionnaire. Confidentiality regarding the participant response for the questions was ensured.

\section{Statistical Analysis}

Data was entered in Microsoft excel and analysis was done using SPSS statistical package version 22.

\section{Result}

Out of 150 participants, $42(28 \%)$ were boys and $108(72 \%)$ were girls, with a mean age of $17.94 \pm 0.82$. Majority (62.6\%) of the participants were city residents. (Table 1)

$57.3 \%$ of the study population wants to pursue specialization, $12 \%$ of the students does not want to pursue specialization and $30.7 \%$ of students had not yet decided whether to pursue specialization or not. (Table 2)

Among the students who wants to pursue specialization majority were interested in clinical branches compared to Community Medicine which was only $6.9 \%$ (Table 3). Majority of males (37\%) were interested in selecting cardiology and most of females $(30 \%)$ want to opt gynaecology. There was significant difference between males and females selection of specialities like cardiology, gynaecology and orthopaedics. (Table 4)

Most common factors for selection of speciality courses were reputation of the speciality $(91.8 \%)$ and Self interest $(76.7 \%)$ followed by early settlement $(53.4 \%)$, to make more money $(51.1 \%)$. (Table 5)
Table 1: Socio demographic profile of the study subjects $(\mathbf{n}=\mathbf{1 5 0})$

\begin{tabular}{|c|c|}
\hline Age distribution & Frequency $(\%)$ \\
\hline $17-18$ yrs & $117(78 \%)$ \\
\hline $19-20$ yrs & $33(22 \%)$ \\
\hline \multicolumn{2}{|c|}{ Mean age $\pm \mathrm{SD}=17.94 \pm 0.82$} \\
\hline \multicolumn{2}{|l|}{ Sex } \\
\hline Males & $42(28 \%)$ \\
\hline Females & $108(72 \%)$ \\
\hline \multicolumn{2}{|l|}{ Residence } \\
\hline Rural & $21(14 \%)$ \\
\hline Town & $35(23.4 \%)$ \\
\hline City & $94(62.6 \%)$ \\
\hline
\end{tabular}

Table 2: Distribution of the study population based of willingness for pursuing specialization $(n=150)$

\begin{tabular}{|l|c|}
\hline \multicolumn{1}{|c|}{$\begin{array}{c}\text { Willing for pursuing } \\
\text { specialization }\end{array}$} & Frequency (\%) \\
\hline Yes & $86(57.3)$ \\
\hline No & $18(12)$ \\
\hline Not yet decided & $46(30.7)$ \\
\hline
\end{tabular}

Table 3: Distribution of the study population based on the selection of speciality $(n=86)$

\begin{tabular}{|l|c|}
\hline \multicolumn{1}{|c|}{ Speciality } & Frequency (\%) \\
\hline Cardiology & $22(25.6)$ \\
\hline Neurology & $15(17.4)$ \\
\hline Gynaecology & $11(12.8)$ \\
\hline Paediatrics & $12(14)$ \\
\hline Gen surgery & $09(10.4)$ \\
\hline Orthopaedics & $07(8.1)$ \\
\hline General Medicine & $04(4.7)$ \\
\hline Community Medicine & $06(7)$ \\
\hline Total & $86(100)$ \\
\hline
\end{tabular}

Table 4: Gender wise distribution of study population based on the preference of speciality $(n=86)$

\begin{tabular}{|l|c|c|c|c|}
\hline \multicolumn{1}{|c|}{ Speciality } & Males (\%) & Females (\%) & Chi square & P value \\
\hline Cardiology & $17(77.2)$ & $5(22.8)$ & 6.72 & 0.009 \\
\hline Neurology & $9(60)$ & $6(40)$ & 0.30 & 0.57 \\
\hline Gynaecology & $0(0)$ & $12(100)$ & 13.63 & 0.0002 \\
\hline Paediatrics & $4(36.4)$ & $7(63.6)$ & 0.80 & 0.37 \\
\hline Gen surgery & $6(66.6)$ & $3(33.3)$ & 0.23 & 0.62 \\
\hline Orthopaedics & $7(100)$ & $0(0)$ & 4.74 & 0.02 \\
\hline General Medicine & $2(50)$ & $2(50)$ & 0.0 & 1 \\
\hline Community Medicine & $1(16.7)$ & $5(83.3)$ & 2.10 & 0.14 \\
\hline Total & $46(53.4)$ & $40(46.6)$ & & \\
\hline
\end{tabular}

Table 5: Distribution of study population based on the factors that influenced for selection of particular Speciality $(n=86)$

\begin{tabular}{|l|c|}
\hline \multicolumn{1}{|c|}{ Factors } & Frequency (\%) \\
\hline Specialty reputation & $79(91.8)$ \\
\hline Self interest & $66(76.7)$ \\
\hline Early settlement & $46(53.4)$ \\
\hline To make more money & $44(51.1)$ \\
\hline Preference of terminal branch & $26(30.2)$ \\
\hline
\end{tabular}

\begin{tabular}{|l|l|}
\hline To involve in health research & $05(5.8)$ \\
\hline Family members advice & $03(3.4)$ \\
\hline Friends/Senior Advice & $03(3.4)$ \\
\hline Less competition & $03(3.4)$ \\
\hline Others & $01(1.1)$ \\
\hline
\end{tabular}

* Total percentage exceeds 100 because of multiple responses 


\section{Discussion}

In the present study, $28 \%$ were boys and $72 \%$ were girls, with a mean age of $17.94 \pm 0.82$. Majority $(62.6 \%)$ of the participants were city residents. The findings were contradicting the findings in the study done by Smitha Bhat et $\mathrm{al}^{6}$ which showed that 130 were males and 120 were females. In the study done by the Neeraj Gour et $\mathrm{al}^{7}$ majority males $(51.05 \%)$ and females $(48.94 \%)$ were almost same in number and majority to age group of 20-23 years $(48.95 \%)$. In the study conducted by Saima Diderichsen et $\mathrm{al}^{5} 58 \%$ were females and $42 \%$ were males.

In the current study that $57.3 \%$ of the study population wants to pursue specialization. Similar findings were observed in the study by Smitha Bhat et $\mathrm{al}^{6}$ in which $78.2 \%$ felt that post-graduation was essential.

In the present study most of the students preferred clinical branches compared to SPM. Some students have shown interest in SPM since they were interested in the field visits conducted during the 1st year. Similar findings were observed in the Neeraj Gour et $\mathrm{al}^{7}$ which showed that $30.9 \%$ showed General Medicine, Pediatrics $(23.3 \%)$ followed by Surgery(14.13\%), Obs and Gynaecology (11.9\%). Similar findings were observed in the study by Smitha Bhat et $\mathrm{al}^{6}$ which showed that $95.26 \%$ of study population wanted to pursue a clinical specialty. The most preferred specialties were internal medicine (48), surgery (46), Obstetrics and Gynaecology (ObG) (24) and paediatrics (28). ${ }^{6}$

Males were more interested in selecting cardiology and orthopaedics and females showed interest in specialities like gynaecology, paediatrics and SPM. Community Medicine was mostly preferred by the females. Females showed more interest in the branches like Gynaecology and paediatrics compared to males. Males preferred super speciality branches, General surgery and orthopaedics. Similar findings were observed in the study by Yousef $\mathrm{K}$ et $\mathrm{al}^{8}$ which showed most preferred specialty expressed by male students was surgery, followed by Internal Medicine and Orthopaedics, while the specialty most preferred by female students was obstetrics and Gynaecology, followed by paediatrics. Similar results were observed in the other studies conducted by Dorsey ER et al, ${ }^{9}$ Mariolis A t al,${ }^{10}$ Avgerinos ED et al,,${ }^{11}$ Egerton EA ${ }^{12}$ and McCord JH et al. ${ }^{13}$ Neeraj Gour et al ${ }^{7}$ study also showed that Medicine (37.63\%), Pediatrics (13.97\%) and Surgery $(23.65 \%)$ were most favorite branches among males whereas Medicine $(24.17 \%)$, Pediatrics $(32.96 \%)$ and Gynaecology $(24.17 \%)$ were among females.

In the current study most common factors for selection of speciality courses were reputation of the speciality (92.9\%) and Self interest (77.6\%). Similar results were observed in the study by Neeraj Gour et $\mathrm{al}^{7}$ which showed that Self interest (76.6\%) was the major factor for selection of speciality followed by more income (45.1\%).

\section{Conclusion}

The present study shows that majority of the medical students wants to pursue specialization and majority showed interest in the clinical branches. Since there were field visits in the Community Medicine in the first year some students also showed interest in Community Medicine. Significant difference between males and females selection of specialities like cardiology, gynaecology and orthopaedics. Most common factors for selection of speciality courses were reputation of the speciality and Self interest followed by early settlement and to make more money.

\section{References}

1. Wright B, Scott I, Woloschuk W, Brenneis F, Bradley J. Career choice of new medical students at three Canadian universities: family medicine versus specialty medicine. CMAJ 2004;170:1920-4.

2. Whether or wither some specialties: a survey of Canadian medical student career interest. Center for Healthcare Policy and Research and Department of Public Health Sciences, University of California, Davis, CA 956168638, USA. BMC Med Educ. 2009 Sept.

3. Pushpa N. Medical scam just got bigger: PG seats for Rs 2 cr. The Economic Times. 2009 June

4. Career decisions by medical students: a profile from India. RAO TV Medical Education:, 1976;10:284-9.

5. Saima Diderichsen, Eva E Johansson, Petra Verdonk, Toine Lagro-Janssen, Katarina Hamberg." Few gender differences in specialty preferences and motivational factors: a cross-sectional Swedish study on last-year medical students" BMC Med Educ. 2013;13:39.

6. Smitha Bhat, Landric d'Souza, Jeffrey Fernandez, "Factors Influencing the Career Choices of Medical Graduates" Journal of Clinical and Diagnostic Research. 2012 February, Vol-6(1): 61-64.

7. Neeraj Gour, Dhiraj Srivastava, Paharam Adhikari, Anumita Shahi, Sharma MK, Mahajan PC. "Specialty Preference Among Medical Students and Factors Affecting It" Online Journal of Health and Allied Sciences, Volume 10, Issue 2; April-June 2011.

8. Yousef K, Dema AZ, Zouhair A, Ahmad A,Mohammad $K$. Factors affecting medical students in formulating their specialty preferences in Jordan. BMC Medical Education 2008;8:32.

9. Dorsey ER, Jarjoura D, Rutecki GW. The influence of controllable lifestyle and sex on the specialty choices of graduating U.S. medical students, 1996-2003.Acad Med 2005;80:791-796.

10. Mariolis A, Mihas C, Alevizos A, Gizlis V, Mariolis T et al. General Practice as a career choice among undergraduate medical students in Greece. BMC Medical Education 2007;7:15.

11. Avgerinos ED, Msaouel P, Koussidis GA, Keramaris NC, Bessas Z, Gourgoulianis K. Greek medical students' career choices indicate strong tendency towards specialization and training abroad. Health Policy 2006;79:101-106.

12. Egerton EA. Career preferences enquiry among Queen's University Medical undergraduates and graduates: a follow-up. Medical Education 1983;17:105-111. 
13. McCord JH, McDonald R, Leverson G, Mahvi DM,

Rikkers LF, Chen HC et al. Motivation to pursue surgical. 